Donald R. Miller MD, Raymond J. Martineau MD, J. E. Wynands MD, Jeremy Hill MSc

\title{
Bolus administration of esmolol for controlling the haemodynamic response to tracheal intubation: the Canadian multicentre trial
}

A multicentre trial was designed to determine the dose-response and side-effects of esmolol when administered as a single iv bolus prior to induction of anaesthesia for controlling the haemodynamic response to tracheal intubation. Five hundred and forty-eight patients from 12 university-affiliated centres across Canada were randomized prospectively to receive either placebo (PLAC) or esmolol (E) in a dose of $100 \mathrm{mg}$ (E100) or $200 \mathrm{mg}$ (E200). Study medication was given immediately before induction of anaesthesia with thiopentone 3-5 $\mathrm{mg} \cdot \mathrm{kg}^{-1}$ and succinylcholine $1.5 \mathrm{mg} \cdot \mathrm{kg}^{-1}$. Low-dose narcotic (fentanyl 2-3 $\mu \mathrm{g} \cdot \mathrm{kg}^{-1}$ or sufentanil $0.3 \mu \mathrm{g} \cdot \mathrm{kg}^{-1}$ ) or moderate dose narcotic (fentanyl 4-7 $\mu \mathrm{g} \cdot \mathrm{kg}^{-1}$ ) was also given at five of the participating centres, whereas patients in the remaining seven centres received no narcotic. Patients who received PLAC and no narcotic had greater $H R$ and SBP values after tracheal intubation than patients who received either E100 or E200 ( $P<0.005)$. The proportion of patients whose maximum HR exceeded 110 $\mathrm{min}^{-1}$ was also greater in the PLAC group (22/180) than in

\section{Key words}

ANAESTHESIA: general;

COMPLICATIONS: hypertension, tachycardia;

INTUBATION, TRACHEAL: cardiovascular responses;

SYMPATHETIC NERVOUS SYSTEM: beta-adrenergic blocking drugs: esmolol.

From the Departments of Anaesthesia, Ottawa General Hospital and The Heart Institute, Ottawa Civic Hospital and The University of Ottawa.

Presented at the Annual Meeting of The Canadian Anaesthetists' Society, Québec City, Québec, June 21-25, 1991.

Supported by a research grant from DuPont Pharmaceuticals, Canada.

Address correspondence to: Dr. Donald R. Miller, Department of Anaesthesia, Ottawa General Hospital, 501 Smyth Road, Ottawa, Ontario K1H 8L6.

Accepted for publication 21st May, 1991. either the E100 (10/187) or E200 (9/181) groups $(P<0.05)$, but was not different when comparing E100 with E200. Esmolol was less effective in controlling blood pressure, but, in combination with low-dose narcotic, esmolol suppressed the SBP response to tracheal intubation. In the presence of moderatedose narcotic, however, a decrease in SBP occurred in all three groups following induction of anaesthesia $(P<0.003)$, with the largest decrease $(17 \pm 4 \%)$ occurring in patients who had received $E 200$. The overall incidence of hypotension $(S B P<90$ $\mathrm{mmHg}$ ) was greater in the E200 group (33\%) than either the E100 (25\%) or PLAC (16\%) groups $(P<0.05)$. Other side-effects, such as bradycardia, bronchospasm or pain on injection, occurred no more frequently in either esmolol group than with placebo. It is concluded that a $100 \mathrm{mg}$ bolus of esmolol is safe and effective for controlling the haemodynamic response to tracheal intubation. This dose of esmolol combined with a low dose of narcotic (fentanyl $2-3 \mu \mathrm{g} \cdot \mathrm{kg}^{-1}$ or equivalent) results in effective control of both heart rate and blood pressure, while avoiding important side-effects.

Une étude multicentrique fut conçue afin de déterminer la dose-réponse et les effets secondaires de l'esmolol lorsqu'administré en un bolus intraveineux unique avant l'induction de l'anesthésie pour contrôler la réponse hémodynamique à l'intubation trachéale. Cinq cent quarante-huit patients de 12 centres affiliés à l'université à travers le Canada furent randomisés d'une façon prospective afin de recevoir soit $d u$ placebo (PLAC) ou de l'esmolol (E) à des doses de $100 \mathrm{mg}$ (E100) ou 200 (E200). Le médicament à l'étude fut administré immédiatement avant l'induction de l'anesthésie avec du thiopentone 3-5 $\mathrm{mg} \cdot \mathrm{kg}^{-1}$ et du succinylcholine $1,5 \mathrm{mg} \cdot \mathrm{kg}^{-1}$. Des faibles doses de narcotiques (fentanyl 2-3 $\mu \mathrm{g} \cdot \mathrm{kg}^{-1}$ ou du sufentanil $0,3 \mu \mathrm{g} \cdot \mathrm{kg}^{-1}$ ) ou une dose modérée de narcotique (fentanyl 4-7 $\mu \mathrm{g} \cdot \mathrm{kg}^{-1}$ ) a été administrée à cinq des centres participants, alors que les patients dans les sept autres centres n'ont reçu aucun narcotique. Les patients avant reçu du PLAC et aucun narcotique ont présenté des fréquences cardiaques et une pression systolique artérielle lors de l'intubation plus 
élevées que les patients avant reçu soit E100 ou E200 (P< $0,005)$. La proportion des patients chez qui la fréquence cardiaque maximale exéda $110 \mathrm{~min}^{-1}$ fut encore supérieure dans le groupe PLAC (22/180) que ceux des groupes E100 (10/187) ou E200 (9/181) $(P<0,05)$, mais ne fut pas différente lorsqu' on compare E100 avec E200. L'esmolol était moins efficace pour contrôler la pression artérielle mais en combinaison avec des narcotiques à faible dose, l'esmolol a aboli la réponse hypertensive lors de l'intubation trachéale. En présence de doses modérées de narcotiques, cependant, une diminution de la pression systolique est survenue chez tous les trois groupes après induction de l'anesthésie $(P<0,001)$, et la plus grande diminution $(17 \pm 4 \%)$ est survenue chez les patients ayant reçu E200 $\mathrm{mg}$ d'esmolol. L'incidence générale d' hypotension (SBP $<90 \mathrm{mmHg}$ ) fut plus grande chez le groupe E200 (33\%) que ceux du groupe EIOO (25\%) ou PLAC (16\%) (P< $0,05)$. Les autres effets secondaires, tels que bradycardie, bronchospasme ou douleur au site d'injection, sont survenus à égale fréquence dans le groupe esmolol et groupe placebo. On conclut que $100 \mathrm{mg}$ d' esmolol en bolus est sécuritaire et efficace pour contrôler la réponse hémodynamique à l'intubation trachéale. Cette dose d'esmolol combinée avec de faibles doses de narcotiques (fentanyl 2-3 $\mu \mathrm{g} \cdot \mathrm{kg}^{-1}$ ou équivalent) a amené un contrôle efficace de la fréquence cardiaque et de la pression artérielle, tout en évitant des effets secondaires importants.

The use of $\beta$-adrenergic blocking drugs for the treatment of angina pectoris, hypertension and arrhythmias is now well-established. ${ }^{1,2}$ It has also become common practice in anaesthesia to give increments of propranolol to control tachycardia intraoperatively in patients at risk for developing myocardial ischaemia, but there is concern about the long duration of action of this drug. Esmolol (methyl3-[4-(2-hydroxy-3-[isopropylamino]propxy)phenyl]proprionate) is a new ultra-short-acting cardioselective $\beta_{1}$ adrenergic blocking drug which has ideal properties for use in the perioperative period.

Compared with other $\beta$-blocking drugs, esmolol is characterized by its cardioselectivity, rapid onset of action, and extremely short elimination half-life of $9.2 \pm$ $2.0 \mathrm{~min} .{ }^{3}$ Esmolol has an apparent volume of distribution of $3.4 \pm 1.4 \mathrm{~L} \cdot \mathrm{kg}^{-1}$ and a distribution half-life of $2.0 \pm$ $0.5 \mathrm{~min} .{ }^{4,5}$ The drug is metabolized very rapidly, as a result of hydrolysis by red blood cell esterases to form methanol and an inactive metabolite. Esmolol achieves peak effect on heart rate within one minute, and on blood pressure within two minutes of intravenous injection. ${ }^{5}$

These pharmacokinetic and pharmacodynamic properties make esmolol suitable for administration by either continuous infusion or bolus injection. Initial studies showed that infusion of esmolol is efficacious in preventing tachycardia and hypertension at the time of tracheal intubation, and in reducing the incidence of myocardial ischaemia during the prebypass period in patients undergoing coronary artery surgery. ${ }^{6-9}$ It was recognized, however, because of esmolol's rapid onset and short duration of action, that bolus injection might be a simple and effective alternative to infusion of this drug in situations involving transient hyperdynamic cardiovascular events. Therefore, beginning in October 1987, a multicentre, placebo-controlled trial was undertaken to determine the efficacy and safety of bolus administration of esmolol for attenuating the hyperdynamic cardiovascular response to tracheal intubation.

\section{Methods}

\section{Patient population}

Five hundred and forty-eight patients from 12 universityaffiliated centres across Canada entered this randomized, placebo-controlled double-blind study. All patients provided written informed consent and the protocols were approved by an institutional review board or its local equivalent. Subjects were at least $18 \mathrm{yr}$ of age, and scheduled to undergo elective non-cardiac surgery under general anaesthesia. At six of the 12 participating centres, patients had either a history of coronary artery disease (CAD) or two or more CAD risk factors. Patients were excluded if their average ward heart rate and systolic blood pressure were less than $60 \mathrm{~min}^{-1}$ and $110 \mathrm{mmHg}$ respectively. The diagnosis of sick sinus syndrome or conduction abnormality on the preoperative ECG, congestive heart failure or myocardial infarction within the previous three to six months, or a history of bronchospastic disease resulted in exclusion from the trial. Furthermore, patients receiving adrenergic-augmenting and depleting drugs (including MAO inhibitors and reserpine) were excluded from the study. In three of the 12 centres, patients who were taking $\beta$-adrenergic blocking drugs were allowed to continue their usual medications; in the remaining nine centres, patients were not included if they had received propranolol, pindolol, timolol or atenolol within $24 \mathrm{hr}$ of the study, or nadolol within the previous four days.

\section{Study medication}

Esmolol $\mathrm{HCl} 10 \mathrm{mg} \cdot \mathrm{ml}^{-1}$ was supplied in $10 \mathrm{ml}$ USP Type I amber glass vials in an acetate buffer for injection. Placebo was given in the form of vehicle. At each centre, the medication was distributed by the hospital pharmacy in coded labelled vials in order to prevent group identification by the investigator. During the anaesthetic induction sequence, each patient received the study medication or placebo according to random assignment in blocks of 45 for each centre, into one of three following treatment groups: 
PLAC $=$ Placebo

$\mathrm{E} 100=$ Esmolol $100 \mathrm{mg}$

E200 = Esmolol $200 \mathrm{mg}$

\section{Protocol}

All usual cardiovascular medications were administered up to and including the morning of surgery. The majority of patients $(n=413)$ received premedication consisting of either oral diazepam 5-15 mg or lorazepam 2-4 mg given $60-90 \mathrm{~min}$ preoperatively. In one centre $(n=45)$ a combination of oral diazepam 5-15 mg, morphine 5-7 $\mathrm{mg}$ im and glycopyrrolate $0.2 \mathrm{mg}$ im was given $60-90$ min preoperatively, whereas patients in two of the centres $(n=90)$ were unpremedicated.

On arrival in the operating room, an intravenous line was initiated, and in 121 patients an arterial cannula was inserted under local anaesthesia prior to induction. In addition to monitoring lead II of the ECG, a $\mathrm{V}_{5}$ or $\mathrm{CM}_{5}$ lead was also applied and monitored continuously in patients who had risk factors for coronary artery disease. Following application of the monitors, patients in all but one centre $(n=45)$ received a defasciculating dose of either d-tubocurarine or pancuronium. Next, patients received, at the discretion of the study centre, either low-dose narcotic (fentanyl $2-3 \mu \mathrm{g} \cdot \mathrm{kg}^{-1}$ or sufentanil $0.3 \mu \mathrm{g} \cdot \mathrm{kg}^{-1}$ ), moderate-dose narcotic (fentanyl 4-7 $\mu \mathrm{g} \cdot \mathrm{kg}^{-1}$ ), or no narcotic.

Patients were then preoxygenated with $100 \% \mathrm{O}_{2}$ for three minutes, after which the study medication was administered intravenously over $15 \mathrm{sec}$, followed immediately by induction of anaesthesia with thiopentone 3-5 $\mathrm{mg} \cdot \mathrm{kg}^{-1}$ and administration of succinycholine 1.5 $\mathrm{mg} \cdot \mathrm{kg}^{-1}$. In one centre (45 patients), esmolol was given just after, rather than prior to induction with thiopentone and succinylcholine. Direct laryngoscopy and tracheal intubation (503 patients) or rigid bronchoscopy (45 patients) were performed 60-90 sec following induction of anaesthesia. Maintenance of anaesthesia consisted of $66 \%$ nitrous oxide with low concentrations of either enflurane or isoflurane (458 patients), nitrous oxide only (45 patients), or supplemental boluses of thiopentone in the centre ( 45 patients) where rigid bronchoscopies were performed. Muscle relaxation was maintained using either atracurium or vecuronium, or succinylcholine by infusion. For the multicentre analysis, the study protocol was completed six minutes after airway instrumentation, following which patients were managed according to the discretion of their attending anaesthetist.

\section{Measurements}

For each haemodynamic variable, data collection was standardized by recording baseline (BL) measurements from the mean of three values measured at one minute intervals prior to induction of anaesthesia. Measurements were again recorded $30-60 \mathrm{sec}$ following induction (IND), and every minute for six minutes following intubation (INT $+1 \ldots . . \mathrm{INT}+6)$. Surgery did not commence in any patient until the study protocol had been completed. Heart rate (HR), systolic (SBP) and diastolic (DBP) blood pressures were measured using an automated, non-invasive blood pressure monitoring device in $78 \%$ of patients, and from the digital display of the arterial line inserted prior to induction of anaesthesia in the remainder (three centres). All adverse clinical events occurring during the study period were recorded in the Case Record Forms. For the statistical analysis, hypotension was defined as a systolic blood pressure $<90 \mathrm{mmHg}$, and bradycardia was defined as $\mathrm{HR}<50 \cdot \mathrm{min}^{-1}$.

\section{Statistical analysis}

Analysis of covariance (ANOCOVA) was performed to identify haemodynamic differences among groups at each time period. Baseline values were used as the covariate. A $2 \times 2$ analysis of variance (ANOVA) was also used to compare the maximum percent changes of both $H R$ and SBP in response to induction of anaesthesia and tracheal intubation. To control for the influence of baseline measurements, these maximal changes were also compared using ANOCOVA, with baseline values serving as the covariate.

A correlation matrix was generated for pairs of variables to determine the influence of age, body weight, premedication, opiate analgesic, and thiopentone dose on the maximum cardiovascular response to intubation using multiple regression analysis. Analysis of variance and ANOCOVA were applied to ratio data when homoscedasticity was not rejected and, in cases of variance heterogeneity, Kruskal-Wallis analysis of variance and MannWhitney tests were used. Finally, Chi-square analysis was applied to the demographic variables. Data are presented as mean values $\pm 95 \%$ confidence intervals (CI) in the text, tables and figures. Statistical significance was assumed when $P<0.05$.

\section{Results}

\section{Study population}

The demographic data of the 548 patients who completed the study protocol are presented in Tables I and II. The patient population had a mean age of $56 \pm 16 \mathrm{yr}$, and the groups were similar with respect to weight, sex distribution, ASA classification and preoperative blood pressure. The incidence of documented coronary artery disease (CAD) was 8.9-12.8\%, but there were also a number of associated CAD risk factors in each group, including vascular disease, obesity, hypertension, diabetes, and smoking (Table II). The frequencies presented in Table II may underestimate the true incidence of these risk factors, 
TABLE I Demographic data

\begin{tabular}{lccc}
\hline & PLAC & E100 & E200 \\
\hline Patients (n) & 180 & 187 & 181 \\
Age (yr) & $56 \pm 16$ & $56 \pm 16$ & $55 \pm 16$ \\
Sex (M/F) & $85 / 95$ & $90 / 97$ & $88 / 93$ \\
Weight (kg) & $71 \pm 14$ & $72 \pm 17$ & $71 \pm 14$ \\
ASA (n/class) & & & \\
$\quad$ I & $40(22.2 \%)$ & $34(18.2 \%)$ & $39(21.5 \%)$ \\
II & $97(53.8 \%)$ & $96(51.3 \%)$ & $95(52.4 \%)$ \\
III & $42(23.3 \%)$ & $56(29.9 \%)$ & $44(24.3 \%)$ \\
IV & $1(0.6 \%)$ & $1(0.6 \%)$ & $3(1.6 \%)$ \\
SBP (mmHg) & $143 \pm 26$ & $141 \pm 24$ & $143 \pm 23$ \\
DBP (mmHg) & $76 \pm 12$ & $77 \pm 11$ & $78 \pm 12$ \\
\hline
\end{tabular}

The demographic variables. PLAC $=$ placebo, $\mathrm{E} 100=$ esmolol $100 \mathrm{mg}$ bolus, $\mathrm{E} 200=$ esmolol $200 \mathrm{mg}$ bolus; $\mathrm{ASA}=$ American Society of Anesthesiologist's physical status classification; SBP = preoperative ward systolic blood pressure; $\mathrm{DBP}=$ preoperative ward diastolic blood pressure.

TABLE II Associated cardiovascular diseases

\begin{tabular}{lccc}
\hline & PLAC & $E 100$ & $E 200$ \\
\hline Patients $(n)$ & 180 & 187 & 181 \\
CAD & $8.9 \%$ & $12.8 \%$ & $11.1 \%$ \\
PVD & $24.4 \%$ & $22.4 \%$ & $25.4 \%$ \\
AAA & $3.9 \%$ & $9.6 \%$ & $6.1 \%$ \\
Hypertension & $33.9 \%$ & $28.3 \%$ & $23.2 \%$ \\
Diabetes & $10.6 \%$ & $7.5 \%$ & $8.3 \%$ \\
Obesity & $7.2 \%$ & $10.7 \%$ & $6.6 \%$ \\
Smokers & $28.3 \%$ & $34.8 \%$ & $35.9 \%$ \\
\hline
\end{tabular}

The percentage of patients in each of the three groups (PLAC, E100, E200) with associated coronary artery disease (CAD) or known CAD risk factors. $\mathrm{PVD}=$ peripheral vascular disease; $\mathrm{AAA}=$ abdominal aortic aneurysm.

TABLE III Preoperative cardiovascular medications

\begin{tabular}{lccc}
\hline & PLAC & E100 & E200 \\
\hline Patients $(n)$ & 180 & 187 & 181 \\
BB & $11 \%$ & $7 \%$ & $7 \%$ \\
CEB & $8 \%$ & $10 \%$ & $8 \%$ \\
Nitrates & $6 \%$ & $6 \%$ & $4 \%$ \\
Other & $21 \%$ & $20 \%$ & $14 \%$ \\
\hline
\end{tabular}

The percentage of patients in each of the three groups (PLAC, E100, E200) receiving chronic cardiovascular medications. $\mathrm{BB}=$ betaadrenergic blocking drugs; $C E B=$ calcium entry blocking drugs.

as this information was not recorded at all study centres. A total of 45 patients $(8 \%)$ was receiving chronic $\beta$ adrenergic blocker therapy upon entry into the study, whereas $9 \%$ were on calcium entry blocking drugs, with an equal distribution amongst the three treatment groups (Table III). The proportion of patients taking other cardioactive medications (including cardiac glycosides and diuretics) was also similar amongst the three groups.

\section{Premedication and narcotic supplementation}

Four hundred and thirteen of the 548 patients $(75.4 \%)$ received premedication with a benzodiazepine consisting of oral diazepam 5-15 mg or lorazepam 2-4 mg given $60-90 \mathrm{~min}$ preoperatively. Forty-five patients $(8.2 \%)$ received a combination of oral diazepam $5-15 \mathrm{mg}$, morphine $5-7 \mathrm{mg}$ im and glycopyrrolate $0.2 \mathrm{mg} \mathrm{im}$, while the remainder of subjects $(16.4 \%)$ was unpremedicated.

The majority of patients $(n=299 ; 54.5 \%)$ received no narcotic during the study period. One hundred and eighty-four (33.6\%) subjects received a low-dose narcotic (either fentanyl 2-3 $\mu \mathrm{g} \cdot \mathrm{kg}^{-1}$ or sufentanil $0.3 \mu \mathrm{g} \cdot \mathrm{kg}^{-1}$ ) prior to induction of anaesthesia, and $65(11.9 \%)$ received a moderate-dose narcotic (fentanyl 4-7 $\mu \mathrm{g} \cdot \mathrm{kg}^{-1}$ ). The patients who received the supplemental narcotics were equally distributed among the three treatment groups.

\section{Effect of esmolol on the haemodynamic response to intubation}

The chronotropic and pressor responses during the induction-intubation sequence for patients who received esmolol without narcotics are presented in Figure 1. Induction caused an increase in HR from $77 \pm 5$ to $89 \pm$ $3 \mathrm{~min}^{-1}$ in the PLAC group $(P<0.005)$, but HR was unchanged after induction in both the E100 and E200 groups (Figure 1, Panel A). Tracheal intubation resulted in a further increase of HR in the PLAC group, reaching a peak value of $99 \pm 3.6 \mathrm{~min}^{-1}$ two minutes after the stimulus. In contrast, both doses of esmolol were effective in maintaining mean $\mathrm{HR}$ below $85 \mathrm{~min}^{-1}$ throughout the study period.

Following induction of anaesthesia, mean SBP did not change significantly in the PLAC group, but decreased by $13 \pm 3 \mathrm{mmHg}$ with $\mathrm{E} 100(P<0.005)$, and by $23 \pm 3$ $\mathrm{mmHg}$ with E200 $(P<0.005$, Figure 1, Panel B). After tracheal intubation, an increase in systolic pressure occurred in all three groups, but the $36 \pm 4 \%$ increase (peak value $178 \pm 8 \mathrm{mmHg}$ ) of SBP in the PLAC group was greater than the $24 \pm 3 \%$ and $18 \pm 4 \%$ maximum increases observed with E100 and E200 respectively $(P<$ $0.005)$.

\section{Influence of opiate analgesics on the cardiovascular response to intubation}

The cardiovascular changes during the inductionintubation sequence for patients who received both low-dose and moderate-dose narcotic are presented in Figure 2. For patients who received low-dose fentanyl or sufentanil, induction of anaesthesia produced decreases in both HR and SBP in the E100 $(P<0.001)$ and E200 groups $(P<0.001)$ compared with the PLAC group (Figure 2, panels A and B). However, following intubation in the PLAC group, there was an increase in HR to 87 $\pm 5 \min ^{-1}(P<0.001)$ and an increase in SBP to $153 \pm$ 

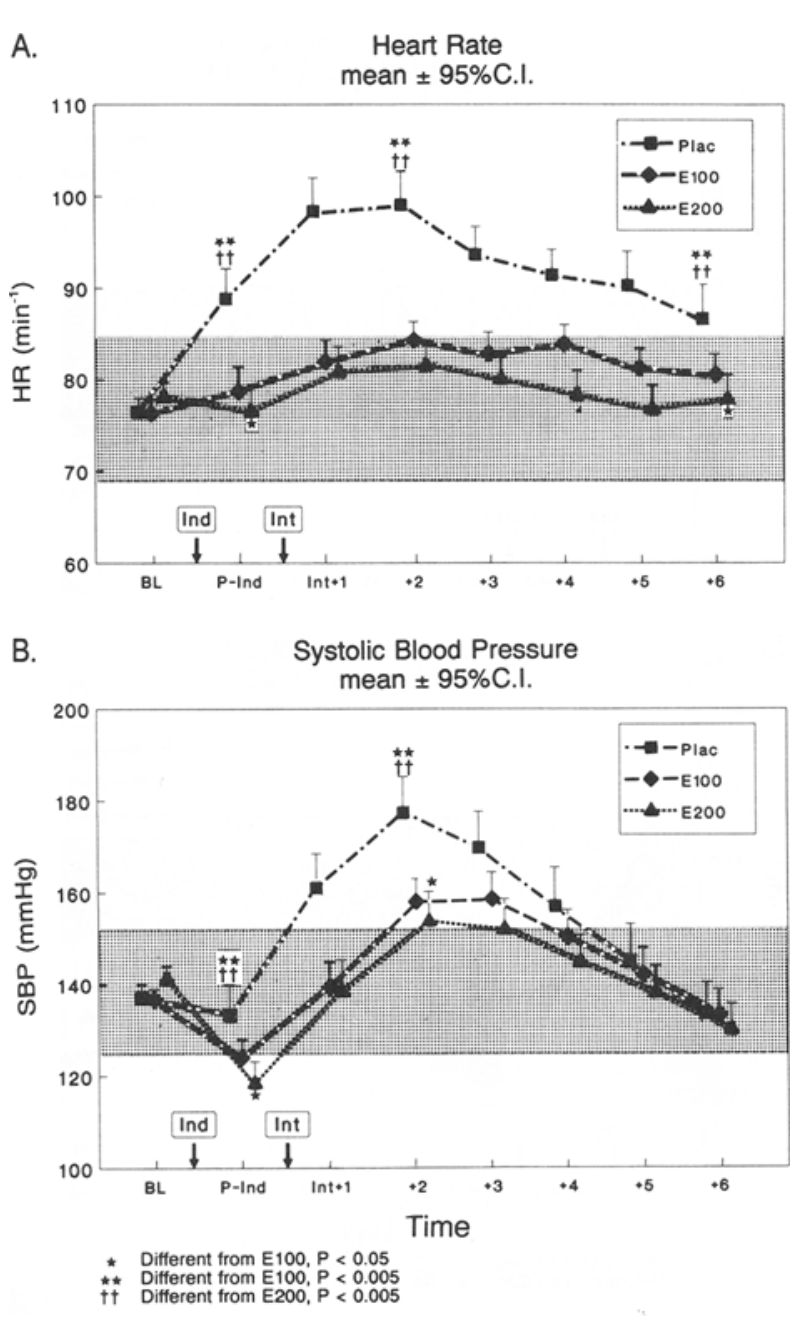

FIGURE 1 The effects of esmolol on HR (Panel A) and SBP (Panel $B$ ) in response to induction (IND) of anaesthesia and the first six minutes following intubation (INT $+1 \ldots+6) . \mathrm{BL}=$ baseline; P-IND $=$ post - induction $; \mathrm{PLAC}=$ placebo $; \mathrm{E} 100=$ esmolol $100 \mathrm{mg}$; E200 $=$ esmolol $200 \mathrm{mg}$. Differences are specified when ANOCOVA was significant $(P<0.05)$ at $P-I N D$ and at INT +2 . The stippled areas represent the mean $\pm 10 \%$ of BL values for both HR and SBP.

$12 \mathrm{mmHg}(P<0.001)$, whereas the maximum HR and SBP changes following intubation with E100 and E200 were not different from pre-induction values.

Patients who received moderate-dose narcotic experienced no significant change in HR either after induction or in response to tracheal intubation (Figure 2, Panel C). In contrast, moderate-dose narcotic was associated with a significant decrease of SBP in all three groups following induction of anaesthesia, and SBP remained significantly depressed compared to baseline values after tracheal intubation and throughout the study period (Figure 2, Panel D).

In order to delineate better the effects of narcotic administration, the maximum percent changes of $\mathrm{HR}$ and SBP in response to induction and tracheal intubation were calculated and are displayed in Figure 3. This figure demonstrates that compared with placebo, both 100 and $200 \mathrm{mg}$ doses of esmolol significantly attenuated, but did not completely suppress, the maximum HR and SBP response to tracheal intubation. In the presence of lowdose narcotic, the maximum HR response to intubation was not different from baseline in either esmolol group, and SBP increased by only $5 \pm 3 \%$ in the E100 group $(P<0.01$, Figure 3, Panels $\mathrm{C}$ and D). In contrast, moderate-dose narcotic resulted in a decrease $(P<0.001)$ in systolic blood pressure not only in both esmolol groups, but in the placebo group as well.

Overall, the proportion of patients whose HR increased above $110 \mathrm{~min}^{-1}$ after tracheal intubation was greater in the PLAC group $(22 / 180)(P<0.05)$ than in the patients who developed this degree of tachycardia following either E100 (10/187) or E200 (9/181). Esmolol prevented SBP from exceeding $180 \mathrm{mmHg}$ in all but $10 / 187$ patients in the E100 group and 8/181 patients in the E200 group, compared with 22/180 patients in the PLAC group whose peak SBP rose above this value $(P<0.05)$. These observed haemodynamic changes were transient, with heart rate and blood pressure returning toward baseline values within six minutes of tracheal intubation in all groups.

\section{Other factors which independently influenced the maximum cardiovascular response to tracheal intubation}

Multiple regression analysis revealed that baseline values of heart rate and systolic blood pressure could independently influence the maximum cardiovascular response to intubation. Maximal changes for both variables were inversely related to respective baseline recordings, in such a way that higher baseline values tended to decrease the magnitude of responses which occurred following airway instrumentation.

Multiple regression analysis also revealed that, in addition to the influence of esmolol and opiate analgesics, premedication was an independent predictor of the maximum blood pressure response following airway instrumentation. For SBP, the best predictability was observed when the patients were unpremedicated, as defined by the relationship: $y=52.6-0.18 \mathrm{a}-5.64 \mathrm{~b}-2.97 \mathrm{c}$, with an adjusted correlation coefficient $=0.602$ (where $y=$ predicted change in SBP, $a=$ baseline SBP, $b=$ fentanyl dose, and $\mathrm{c}=$ esmolol dose). For patients who received premedication with a benzodiazepine, the adjusted $r^{2}$ was 0.397 , whereas for patients who received a combination of diazepam and morphine preoperatively there was little correlation with the maximum SBP response to intubation (adjusted $r^{2}=0.144$ ). Thus, benzodiazepine premedica- 
A.

Low Dose Narcotic

HR (mean $\pm 95 \%$ C.I.)

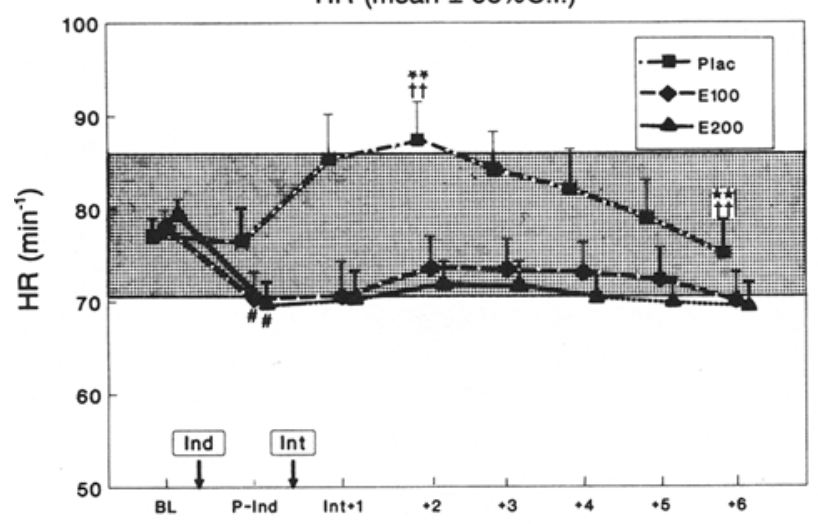

$\begin{array}{ll}\text { B. } & \text { Low Dose Narcotic } \\ & \operatorname{SBP}(\text { mean } \pm 95 \% \text { C.I.) }\end{array}$

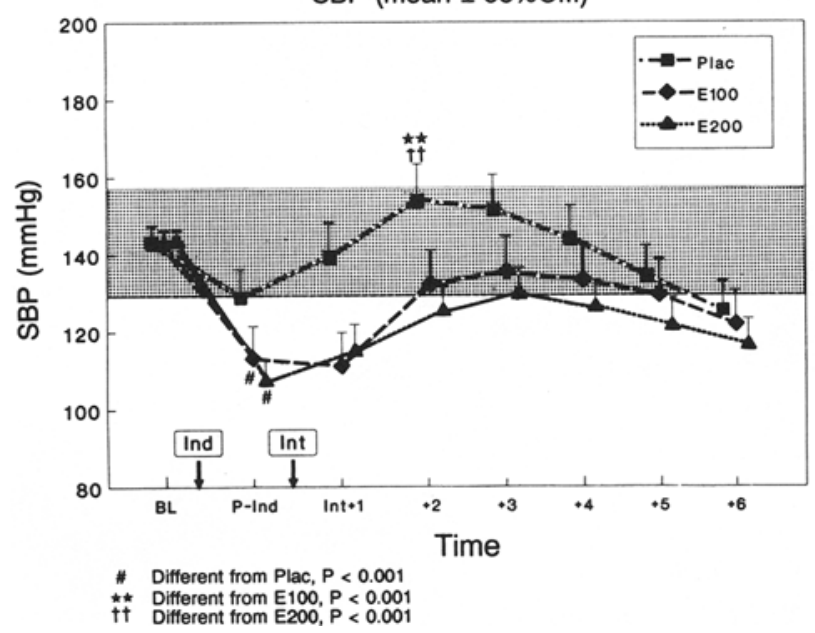

C. Moderate Dose Narcotic

HR (mean $\pm 95 \%$ C.I.)

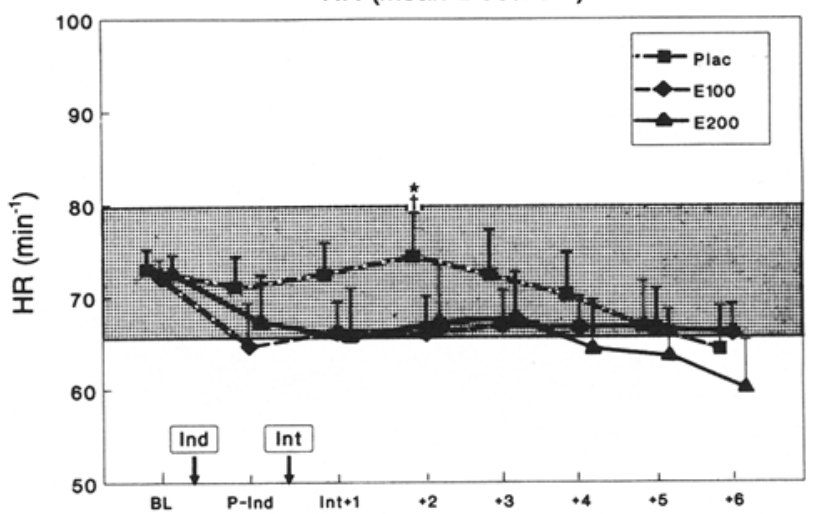

D.

Moderate Dose Narcotic

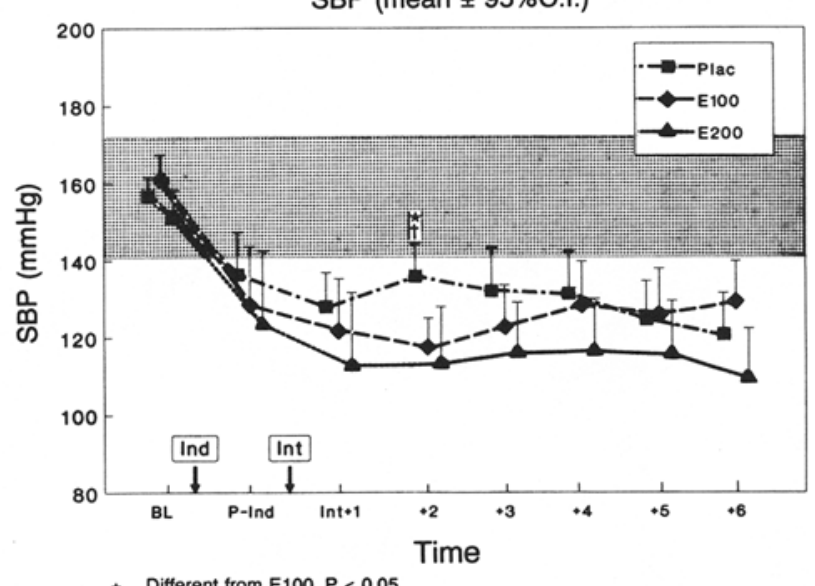

Different from E100, $P<0.05$
Different from E200, $P<0.05$

FIGURE 2 The effects of low- and moderate-dose narcotics on HR (Panels A and B) and SBP (panels C and D) in response to induction of anaesthesia and tracheal intubation in the PLAC, E100 and E200 groups. Differences are specified when ANOVA was significant $(P<0.05)$ at $\mathrm{P}-\mathrm{IND}$ and at INT +2 . The stippled areas represent the mean $\pm 10 \%$ of $\mathrm{BL}$ values for both HR and SBP. For abbreviations refer to legend of Figure 1.

tion had an independent moderating effect on the maximum blood pressure response to tracheal intubation. In contrast, the choice of premedication was found to have no significant influence on the maximum heart rate response to airway instrumentation.

Factors which had no influence on the cardiovascular response to tracheal intubation

Forty-five of the 548 patients were receiving treatment preoperatively with $\beta$-adrenergic blocking drugs. These patients tended to have lower heart rates throughout the study period, and a higher incidence of hypotension (SBP $<90 \mathrm{mmHg}$ ) than in their non-beta-blocked counterparts (60\% vs $35 \%, P<0.01$ ). However, $47 \%$ of the chroni- cally $\beta$-blocked subjects also received moderate dose fentanyl, compared with only $9 \%$ of the non $\beta$-blocked patients. Despite lower mean HR and SBP values in these patients, multiple regression analysis showed that the effect of esmolol on the maximum percent change in HR and SBP following intubation was independent of whether or not patients were receiving $\beta$-adrenergic blocking drugs preoperatively.

The mean induction dose of thiopentone was $311 \pm 81$ $\mathrm{mg}$ or $4.4 \mathrm{mg} \cdot \mathrm{kg}^{-1}$. Even over such a range, regression analysis failed to show that the titrated dose of thiopentone could independently predict the maximum cardiovascular response to tracheal intubation. Similarly, age was not found to be a significant predictor of the 
A.

INDUCTION

$\mathrm{HR}$ (max change $\pm 95 \%$ C.I.)

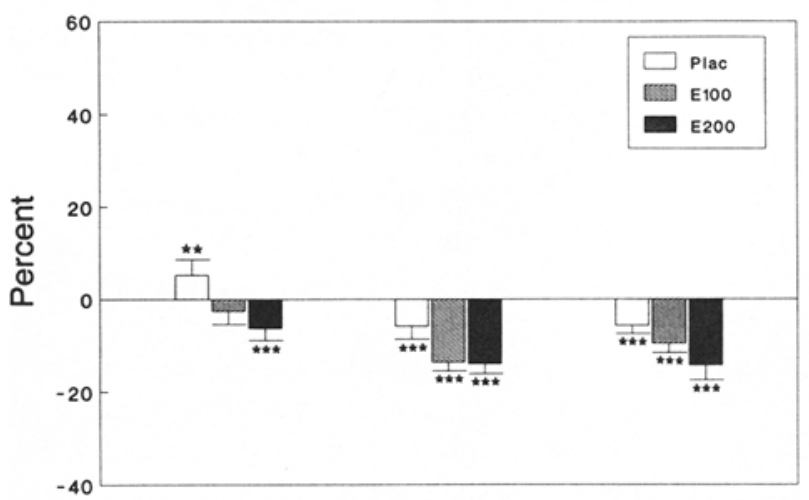

B.

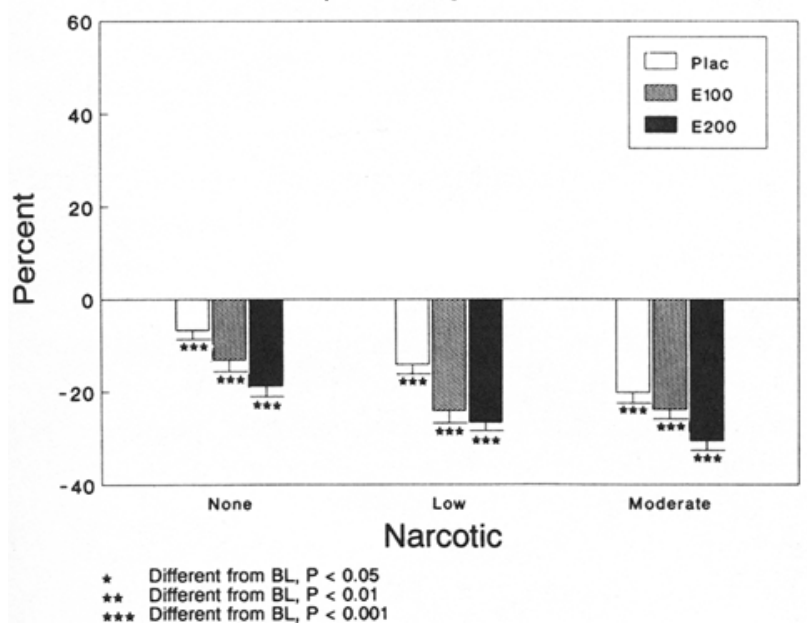

C.

INTUBATION

HR (max change $\pm 95 \%$ C.I.)

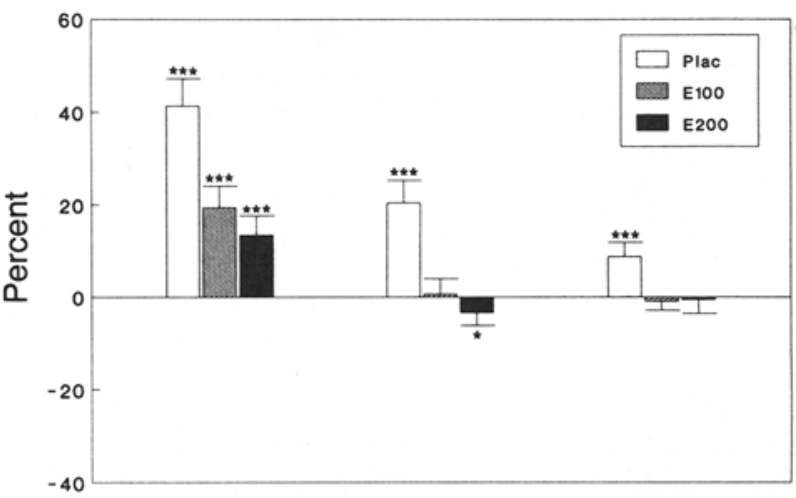

D.

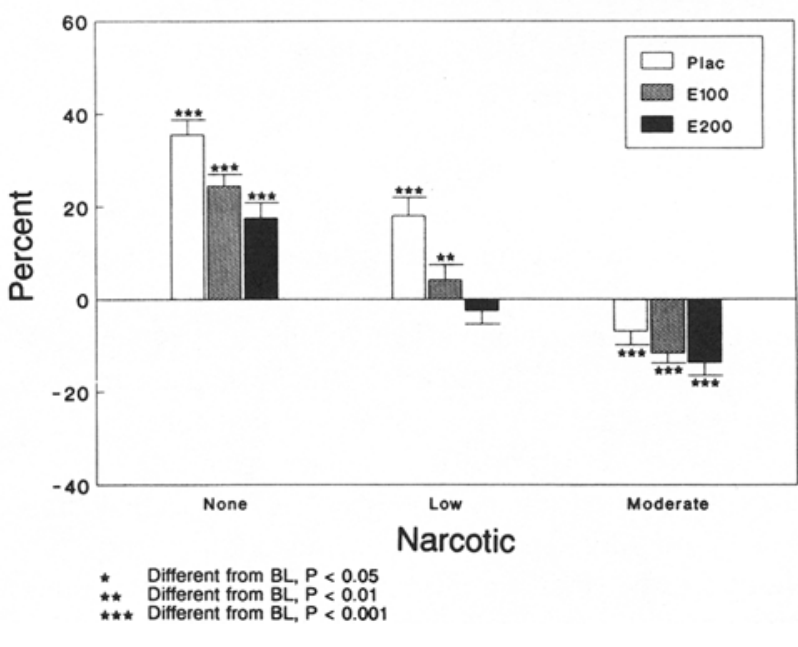

FIGURE 3 The maximum percent changes of HR and SBP in response to induction (Panels $A$ and $B$ ) and tracheal intubation (panels $C$ and D) for PLAC, E100 and E200. Changes from baseline are specified using paired Student's $t$ tests. For abbreviations refer to legend of Figure 1.

maximum heart rate or blood pressure response to tracheal intubation.

\section{Adverse effects}

The adverse effects are summarized in Table IV. The most commonly reported side-effect was hypotension. The proportion of E200 patients (33\%) who became hypotensive (SBP $<90 \mathrm{mmHg}$ ) was greater than the proportion of E100 patients (25\%) who developed this nadir in blood pressure, whereas only $16 \%$ of the PLAC group became hypotensive $(P<0.05$ for E100 vs PLAC, and $P<0.01$ for E200 vs PLAC). Overall, patients who received esmolol with fentanyl in moderate doses had a higher incidence of hypotension than patients who received either low-dose or no narcotic. Fifty-eight patients received treatment for hypotension with ephedrine, phenylephrine, or additional intravenous fluids at the discre-
TABLE IV Adverse events

\begin{tabular}{lccr}
\hline & PLAC & E100 & \multicolumn{1}{l}{ E200 } \\
\hline Patients $(n)$ & 180 & 187 & 181 \\
SBP $<90 \mathrm{mmHg}^{-}(n)$ & $28(16 \%)$ & $47(25 \%)$ & $59(32 \%) \dagger$ \\
HR $<50$ min $^{-1}(n)$ & $5(2.7 \%)$ & $2(1.0 \%)$ & $5(2.7 \%)$ \\
Pain on injection $(n)$ & $3(1.6 \%)$ & $3(1.6 \%)$ & $4(2.2 \%)$ \\
Bronchospasm & $2(2.0 \%)$ & $3(2.6 \%)$ & $1(0.5 \%)$ \\
\hline
\end{tabular}

Adverse events. $\mathrm{SBP}=$ systolic blood pressure; $\mathrm{HR}=$ heart rate. *Different from PLAC, $P<0.05$; † Different from PLAC, $P<0.01$.

tion of individual investigators. Interestingly, however, the proportion of patients who received treatment was no greater in either esmolol group than after placebo. Bradycardia (HR $<50 \mathrm{~min}^{-1}$ ) was relatively infrequent, with an incidence no greater in those patients who 
received E100 (2/187) or E200 (5/181) than in the PLAC group $(5 / 180)$. There were no reported sequelae as a result of either hypotension or bradycardia.

Other adverse events included pain on injection in ten patients $(1.8 \%)$, with the incidence being evenly distributed amongst groups. Bronchospasm occurred in six patients $(1.1 \%)$ : two who had received placebo, three who had received E100, and in only one patient who received E200. There were no deaths or other reported adverse sequelae.

\section{Discussion}

Previous studies have shown that the unique pharmacokinetic behaviour of esmolol makes it well suited for controlling the cardiovascular response to tracheal intubation when using a continuous infusion technique. ${ }^{6-9}$ However, the dosing regimen and time required for preparation of an infusion may add a degree of complexity to the induction process which is often unnecessary. As a practical and simple alternative, the results of this multicentre trial show that esmolol can also be given as an intravenous bolus prior to induction of anaesthesia to control the tachycardia and hypertension secondary to tracheal intubation. A dose of $100 \mathrm{mg}\left(1.4 \pm 0.4 \mathrm{mg} \cdot \mathrm{kg}^{-1}\right)$ was found to be safe and effective. Esmolol $200 \mathrm{mg}(2.8$ $\pm 0.4 \mathrm{mg} \cdot \mathrm{kg}^{-1}$ ) conferred no advantage, and resulted in a greater incidence of hypotension.

These results confirm the findings from other recent clinical trials investigating the effects of bolus administration of esmolol during the peri-induction period. ${ }^{10-14}$ However, the small sample sizes (less than 50) of these studies precluded identification of clinical factors which might independently or interactively influence the cardiovascular response to intubation following bolus administration of esmolol. Further, none of these studies was sufficiently large to provide a comprehensive safety evaluation for consideration of possible adverse events which might be relatively infrequent. The multicentre analysis was done in an attempt to address these important issues.

An important finding of this study was the determination of the interactive effect of esmolol with opiate analgesics. This is clinically relevant because, although esmolol modified the chronotropic response to tracheal intubation, it was less effective in controlling blood pressure. The practice of administering an opiate analgesic prior to airway instrumentation is well established, and fentanyl has been shown to moderate independently the haemodynamic response to tracheal intubation. ${ }^{15,16}$ However, the dose of fentanyl which is necessary to abolish the pressor response completely may be associated with undesirable side-effects, including delayed respiratory depression and, occasionally, hypotension follow- ing administration of thiopentone. The multicentre study showed that the combination of esmolol $100 \mathrm{mg}$ with low-dose narcotic (fentanyl $2-3 \mu \mathrm{g} \cdot \mathrm{kg}^{-1}$ equivalent) resulted in effective control of both heart rate and blood pressure in response to tracheal intubation. In contrast, administration of low-dose narcotic without esmolol did not prevent an increase in HR.

Patients who received moderate-dose fentanyl (4-7 $\mu \mathrm{g} \cdot \mathrm{kg}^{-1}$ ) had a stable chronotropic response throughout the study, but this was achieved at the expense of a decrease in blood pressure following administration of thiopentone. With $100 \mathrm{mg}$ of esmolol this decrease in blood pressure was more pronounced but was transient. However, the decrease in SBP was even greater in the E200 group and was sustained after tracheal intubation. Therefore, when considering the effects on blood pressure and heart rate together, the administration of esmolol 100 $\mathrm{mg}\left(1.4 \pm 0.4 \mathrm{mg} \cdot \mathrm{kg}^{-1}\right)$ with a low-dose narcotic analgesic (fentanyl $2-3 \mu \mathrm{g} \cdot \mathrm{kg}^{-1}$ or equivalent) conferred the greatest degree of haemodynamic stability following tracheal intubation while producing minimal side-effects.

In addition to opiate analgesics, several other factors were found to influence the maximum cardiovascular response to intubation. One factor was the patient's pre-induction haemodynamic status. The maximal changes of heart rate and systolic blood pressure were inversely related to their baseline values, such that patients whose HR and SBP were low prior to induction experienced the largest increase of either variable in response to airway instrumentation. Conversely, patients whose heart rate and blood pressure were elevated prior to induction, perhaps because of greater sympathetic tone and increased anxiety, tended to develop smaller absolute increases in both these variables. Heart rate is a major determinant of myocardial oxygen consumption, and there is increasing evidence that tachycardia is poorly tolerated in the perioperative period in patients with coronary artery disease. Several recent studies have shown that there is an increased incidence of myocardial ischaemia when intraoperative heart rates exceed 110 $\min ^{-1} \cdot{ }^{17-19}$ Accordingly, the rationale for administering esmolol as a bolus is not only to treat transient increases in HR and SBP, but also to prevent $\mathrm{HR}$ values from reaching the ischaemic threshold in patients with known CAD or those who have risk factors for CAD.

The choice of premedication was another factor which influenced the cardiovascular response to tracheal intubation. Benzodiazepine premedication with or without morphine resulted in smaller absolute increases in systolic blood pressure than in patients who were unpremedicated. This relationship did not hold for heart rate, but may simply reflect the uneven distribution of patients who were unpremedicated (16.5\%) compared with the remain- 
der who were. Previous investigators have also demonstrated that benzodiazepine premedication is effective in modifying cardiovascular responses intraoperatively. ${ }^{20}$

Apart from causing a transient decrease in systolic blood pressure during induction of anaesthesia, the incidence of adverse effects following bolus administration of esmolol was no greater than in the placebo group. Esmolol attenuated the chronotropic response to tracheal intubation without inducing bradycardia. It has been shown previously that esmolol in doses of $1.5-3.0 \mathrm{mg} \cdot \mathrm{kg}^{-1}$ does not alter stroke volume or depress left ventricular ejection fraction in patients with preserved cardiac function. ${ }^{12}$ Of equal importance when considering the safety of the acute administration of $\beta$-adrenergic blocking drugs is the potential for inducing bronchospasm. Esmolol has been shown to have cardioselective control, with a 40:1 affinity for $\beta_{1}$ adrenergic receptors in animal studies. ${ }^{21}$ However, the cardioselective dose range of this drug in humans is unknown. Thirty-three percent of the 548 patients in this study were smokers, a factor which is associated with increased airway irritability. Despite this only three patients in the E100 group and one in the E200 group experienced bronchospasm, an incidence which was not different from that in the PLAC group. In no case was the bronchospasm of sufficient severity to warrant treatment with bronchodilators.

This study suffered some of the limitations which are common to all multicentre trials. The most important aspect to consider was that protocols varied from one centre to another with regard to inclusion/exclusion criteria and the choice of premedication. However, each of these factors was controlled according to study site, such that patients in each block of 45 had an equal chance of receiving either placebo or one of the two doses of esmolol. Accordingly, variability in selection criteria, premedication, and narcotic dosage occurred within groups but not between groups. More importantly, the induction sequence with thiopentone and succinylcholine was standardized, as were the doses of esmolol administered. Because the time period being studied was narrow (ten minutes in total), the interaction of confounding variables which could have influenced the treatment effect, such as the selection of agents used to maintain anaesthesia, and the continued stimulation from rigid bronchoscopy in one centre, was minimized.

Finally, our study population included a high proportion of patients with documented CAD or known cardiac risk factors, including age, vascular disease, hypertension, diabetes, obesity and smoking. This population is at increased risk of developing perioperative complications, including tachycardia, hypertension and myocardial ischaemia. We would not advocate the routine use of esmolol for all patients undergoing general anaesthesia. However, when it is imperative to control the haemodynamic response to transient perioperative stimuli, esmolol is a useful adjunct to our therapeutic armamentarium. ${ }^{22}$

In conclusion, a $100 \mathrm{mg}$ iv bolus of esmolol is safe and effective in attenuating the haemodynamic response to tracheal intubation in adult surgical patients. A dose of $200 \mathrm{mg}$ of esmolol is no more effective and is associated with a greater degree of hypotension. When considering effects on heart rate and blood pressure concurrently, the administration of esmolol $100 \mathrm{mg}\left(1.4 \pm 0.4 \mathrm{mg} \cdot \mathrm{kg}^{-1}\right)$ with low-dose narcotic analgesics (fentanyl $2-3 \mu \mathrm{g} \cdot \mathrm{kg}^{-1}$ or equivalent) provides haemodynamic stability following tracheal intubation, while producing minimal sideeffects.

\section{Acknowledgement}

The statistical consultation and data analysis by Richard Moisan and Associates (Montreal) is gratefully acknowledged.

\section{Appendix}

\section{Investigators and study centres}

Dr. B. Hamilton, St. Claire-Mercy Hospital, St. John's; Dr. D. Oxorn and Dr. D. Knox, Halifax Infirmary, Halifax; Dr. J. P. Tetrault and Dr. Y. Claprood, Centre Hospitalier Universitaire, Sherbrooke; Dr. J. Ramsay, Royal Victoria Hospital, Montreal; Dr. J. Penning, Ottawa Civic Hospital, Ottawa; Dr. D. Miller and Dr. R. Martineau, Ottawa General Hospital, Ottawa; Dr. A. Sandler and Dr. L. F. Leitch, The Toronto Hospital, Toronto; Dr. E. Hew and Dr J. Mallon, Mount Sinai Hospital, Toronto; Dr. P. Duke, Health Sciences Centre, Winnipeg; Dr. S. Sheppard and Dr. C. Eagle, Foothills Hospital, Calgary; Dr. H. Vaghadia, Vancouver General Hospital, Vancouver; Dr. C. Cole, University Hospital, Shaughnessy site, Vancouver.

\section{References}

1 Frishman WH. $\beta$-Adrenergic antagonists: new drugs and new indications. N Engl J Med 1981; 305: 500-6.

2 Frishman $W$, Silverman $R$. Clinical pharmacology of the new beta-adrenergic blocking drugs. III. Comparative clinical experience and new therapeutic applications. Am Heart J 1979; 98: 119-31.

3 Sum CY, Yacobi A, Kartzinel R et al. Kinetics of esmolol, an ultra short-acting beta-blocker, and of its major metabolite. Clin Pharmacol Ther 1983; 34: 427-34.

4 Gorczynski $R$, Shaffer J, Lee R. Pharmacology of ASC8052 , a novel beta adrenergic receptor antagonist with an ultrashort duration of action. J Cardiovase Pharmacol 1983; 5: 668-77.

5 Sintetos $A L$, Hulse J, Pritchett EL. Pharmacokinetics and 
pharmacodynamics of esmolol administered as an intravenous bolus. Clin Pharmacol Ther 1987; 41: 112-7.

6 Menkhaus PG, Reves JG, Kissin I et al. Cardiovascular effects of esmolol in anaesthetized humans. Anesth Analg 1985; 64: 327-34.

7 Newsome LR, Roth JV, Hug CC et al. Esmolol attenuates the hemodynamic responses during fentanylpancuronium anaesthesia for aortocoronary bypass surgery. Anesth Analg 1986; 65: 451-6.

8 Girard D, Shulman BJ, Thys DM et al. The safety and efficacy of esmolol during myocardial revascularization. Anesthesiology 1986; 65: 157-64.

9 Murthy VS, Patel KD, Elangovan RG et al. Cardiovascular and neuromuscular effects of esmolol during induction of anaesthesia. J Clin Pharmacol 1986; 65: 157-64.

10 Oxorn D, Knox JWD, Hill J. Bolus doses of esmolol for the prevention of perioperative hypertension and tachycardia. Can J Anaesth 1990; 37: 206-9.

11 Sheppard S, Eagle CJ, Strunin L. A bolus dose of esmolol attenuates tachycardia and hypertension after tracheal intubation. Can J Anaesth 1990; 37: 202-5.

12 Miller DR, Martineau RJ, Hull KA, Hill J. Bolus administration of esmolol for controlling the haemodynamic response to laryngoscopy and intubation: efficacy and effects on myocardial performance. Journal of Cardiothoracic Anesthesia 1990; 4 (Suppl 2): 31-6.

13 Pamass SM, Rothenberg DM, Kerchberger JP, Ivankovich $A D$. A single bolus dose of esmolol in the prevention of intubation-induced tachycardia and hypertension in an ambulatory surgery unit. Journal of Clinical Anesthesia 1990; 2: 232-7.

14 Ebert TJ, Bernstein JS, Stowe DF, Roerig D, Kampine $J P$. Attenuation of hemodynamic responses to rapid sequence induction and intubation in healthy patients with a single bolus of esmolol. Journal of Clinical Anesthesia 1990; 2: 243-52.

15 Dahlgren $N$, Messeter $K$. Treatment of stress response to laryngoscopy and intubation with fentanyl. Anaesthesia 1981; 36: 1022-6.

16 Martin DE, Roseberg H, Aukburg SJ et al. Low dose fentanyl blunts circulatory responses to tracheal intubation. Anesth Analg 1982; 61: 680-4.

17 Slogoff S, Keats AS. Randomized trial of primary anesthetic agents on outcome of coronary artery bypass operations. Anesthesiology 1989; 70: 179-88.

18 Stone JG, Föex $P$, Sear JW, Johnson LL, Khambatta $H J$, Triner $L$. Risk of myocardial ischaemia during anaesthesia in treated and untreated hypertensive patients. $\mathrm{Br} \mathrm{J}$ Anaesth 1988; 61 : 675-9.
19 Stone JG, Föex $P$, Sear JW, Johnson LL, Khambatta HJ, Triner $L$. Myocardial ischaemia in untreated hypertensive patients: effect of a single small oral dose of a beta-adrenergic blocking agent. Anesthesiology 1988; 68: 495-500.

20 Thomson IR, Bergstrom PG, Rosenbloom M, Meatherall $R C$. Premedication and high-dose fentanyl anesthesia for myocardial revascularization. A comparison of lorazepam versus morphine-scopolamine. Anesthesiology 1988; 68: 194-200.

21 Murthy VS, Frishman WH. Controlled beta-receptor blockade with esmolol and restolol. Pharmacotherapy 1988; 8: 168-82.

22 Leslie JB. Bolus dose esmolol for anaesthesia: is there a need? Journal of Clinical Anesthesia 1990; 2: 215-20. 